\title{
Lecture Notes in Social Science: A Senior-Citizen Status and the Government's Welfare Budget, the Stabilization of the Alternatives
}

\author{
Kim Jin \\ Sungkyul University, Paideia Collage, Sungkyuldaehakro-53, Manan-gu, \\ Anyang-city, Kyunggi-do, Korea \\ rekj1004@sungkyul.ac.kr
}

\begin{abstract}
The While spending field configurations, changes in this direction can be seen as being consistent with a direct role in the strengthening of government welfare as society advances. Although the development of a welfare state is to better direct the government to expand the welfare budget for funding it. It should be created that, despite the budget, due to this expansion through the social welfare scheme for the expansion of welfare financing agreement with this decision, recognizing tables for the election may not be a big problem there. In other words, if it is determined through the election that the social welfare system, in which we really need to recognize and an effective welfare system is not billed because they are to be introduced. Most of the construction of welfare expenditure is through social insurance, public assistance, social services and welfare issues which are related to the elderly, is on the rise particularly sharply preferred, but a variety of these expenditues will be the biggest social problems for our country. The aim of this study is to find a political response which measures on government budgets tailored to the rapid increase in the elderly by analyzing the overall status and operational budgets of welfare for the elderly in the welfare budget of the government.
\end{abstract}

Keywords: government welfare budgets, financing plans, the increase in the number of elderly, social problems and policy alternatives

\section{Introduction}

Currently, South Korea has recently developed a welfare state debate in our society which clearly shows how much we pay a lot of attention to the welfare nationwide. The current government has started to hold such a historical task to realize the welfare state sentiment nationwide. Moreover, this year's national budget and the government budget can be seen as an important gauge whether subjectively in that the first budget of this government's organization of a welfare state is willing and able to reflect public sentiment. However, the budget of the government has shown that lack the ability and willingness to reflect the sentiment of the welfare state nationwide. Looking at the total amount of the country's fiscal 2014 budget, 2014's financial expenses in 2013 increased by $4.6 \%$ in contrast to the main budget of 357.7 trillion, revenue is set to decline $0.5 \%$ 370.7 trillion. Accordingly, the social sector expenditure budget has been organized by the government accounted for $29.6 \%$ of total expenditure budget, which changes the configuration of the spending areas that can be viewed as reflecting the adjustment in the budget to expand the welfare budget to reduce the economic sector.

It seems the highest growth rate of the 2014 budget was looking to spend sectoral field of health, welfare and employment increased by $8.7 \%$ compared to 2013 in contrast to the main budget which was assigned to 106 trillion won for this assignment, which is to win the high growth rate than the $6.9 \%$ average annual growth rate of the Lee administration period. $8.7 \%$ growth in social sector spending budget may seem high at first glance, 
however it seems that as was a low growth rate CAGR of $12.6 \%$ compared to the social spending in the past and that much of the government's involvement can be seen as the natural increase of the spending obligations. Participation in government social spending budget of 27.6 trillion won in 2003 and 2008 increased by 49.8 trillion won (excluding the housing sector) (Ministry of Strategy digital budget accounting system, integrated financial statistics), annual average growth rate reached $12.6 \%$. In comparison Pan social welfare budget for next year's increase of Park Geun-hye's government sentiment realizes that the challenge can be seen to be very low.

In addition, it seems that the welfare state is organized by public opinion, unlike the government's claim that the increase was significantly suppressed by destroying the commitment of national tasks related to the budget from the last presidential election, when in fact, it reflected in the budget this year increase by ignoring repeated the Intellectual budget.

After all configuration changes in the spending areas, such direction can be seen as being consistent with a direct role in the strengthening of the welfare of the government along with the advancement of society. Although the development of the welfare state is to better direct the government to expand the welfare budget is funding for it. It should be made that, despite the budget is due to this expansion through the social welfare scheme for welfare expansion financing agreement with this decision, recognizing tables for the election may not be a big problem there. In other words, if it is determined through the election social welfare system that we really need to recognize and effective welfare system is not billed because they are to be introduced. Most of the construction of welfare expenditure is social insurance, public assistance, social services and welfare issues related to the elderly is on the rise particularly sharply preferred, but a variety of made will be the biggest social problems of our country.

\section{Status and Elderly Support Payments and an Aging Index}

\subsection{Status of the Elderly}

Please c Elderly Age-specific aging population is a trend to increase every year by $12.2 \%$ of the total population. In 2013, the percentage of share of the elderly population aged 65 and over and will continue to increase by $3.1 \%$ in 1970 to $12.2 \% 203024.3 \%$, in 2050 is expected to reach a level of $37.4 \%$. In particular, the percentage of the population aged 85 years or more seconds, is expected to increase significantly in 2030 to $2.5 \%$ in 2050 and $7.7 \%$ from $0.9 \%$ in 2013.

In addition, the elderly ratio is projected to rise to $70.7 \%$ in 2030 to 81.1 . The sex ratio of the elderly over the age of 65 in 2013 (number of women per 100 men population) is 70.7 to 2030 is expected to increase significantly by 81.1 . This is because the death rate of men, including the elderly, due to heightened interest for the development of medical technologies and health become increasingly low.

\subsection{The Elderly Support Payments and an Aging Index}

Support payments are support for productive population aged six elderly people are one person, and to $16.7 \%$ in 2013 to provide for the elderly support payments productive population 6 elderly people as one person 16.7. If you continue to have low-birth by 2018, the currently productive population about 5 people in 1,2050 , it is expected to be about 1.4 people support one person. 2013 aging index was 83.3 in the youth population $(0-14$ years) 65 years or older for every 100 people and the aging index reached 83 in 2017 the elderly population is expected to exceed the youth population to 104.1 . 


\subsection{The Region Also Ranks Aging}

In 2013 , the elderly had a high proportion in the Jeonnam Region (21.4\%), Jeonbuk. Gyeongbuk (17.5\%), Gangwon (16.4\%) indicated in the order, such as contrast, low areas in Ulsan (7.8\%), charging the game, Incheon $(9.7 \%)$ were in the order and the like. In particular, Jeonnam, Jeonbuk, Gyeongbuk, Gangwon Province, Chungnam, Chungbuk six degrees elderly population ratio exceeded $14 \%$. County and city and look at the percentage of the population 65 years of age or older to distinguish between 'Goheunggun' is highest with 33.8\%, followed by the net 'Gyeongbuk Palace' and 'Gyeongbuk Gunwi.

\subsection{Older Furniture Rate}

The proportion of elderly people in 2013 households in 2013 elderly people aged owner households with a tendency to increase every year by $19.5 \%$. The rate of older furniture has continued to increase in 2010 to $17.8 \%$ in 2005 from $11.9 \%$ and $15.2 \%$ in 2000. 65 years or older living alone elderly households living alone accounted for $6.9 \%$ of the total of 2013 households, the next in 2035 are expected to continue to increase to $15.4 \%$.

Listings or program commands in the text are normally set in typewriter font, e.g., CMTT10 or Courier.

\section{The Issues of Government of Elderly Welfare Budgets}

Government revenues are expected to improve this year and compared to the economic recovery, such as one year tax earnings impact of the economic downturn of last year, it is expected that its instability will contunially be sluggish, while normalized in 2014 after the economy is expected to gradually recover. Modifications are expected to reduce growth forecasts 2012-2016 planning rather than depending on the integrity of the local tax revenue deficit in 2013 and the acquisition tax cuts.

Seoe revenues Development Bank, Industrial Bank, etc., Overall, the outlook than the '12 - '16 year plan to reduce government stakes in the plan change. However, securing new sources of revenue and increase efforts to Jingsuyul are seeing increasing factors. Transfer of funds that are operating outside the budget system revenue expenditure, environmental improvements and promoting new revenue seoe expansion in the field, according to the Bureau the real estate market downturn. Sharing real estate sales decline in value, Risk Factors, such as the Bank of Korea reduced surplus should remain. Fund revenues are subscriber growth, according to social and wage protection-type income funds continued to increase and expand scheduled to be expected, and this is expected to improve slightly more in '12 - '16 year plan, including insurance rate hikes.

The government's fiscal revenue has spent obligations such as welfare spending increasing demand and economic factors corresponding the need for such spending is among the four largest pension trends and continues to increase. In addition, the pension is due to low birth rates. Ageing is also expected to increase spending obligations and maturing mainly welfare spending and so on. Thus, the total financial obligations while the share of expenditure accounted for the rising expenditure is likely to intensify the rigidity of the deepening financial management and enhance economic vitality despite the difficult financial situation, job creation, it is also actively raise spending needs for growth, including potential expansion. In addition to eliminate wasted resources spent on covering the situation, then necessary while maintaining the financial health promotion is also being raised various legal amendments and new expenditures required to accompany the expansion of local finance and treasury support. Spending structure is needed, such as reform. The stakeholders concern for some sectors is expected to reduce annual expenditure. 
Online version of the volume will be available in LNCS Online. Members of institutes subscribing to the Lecture Notes in Computer Science series have access to all the pdfs of all the online publications. Non-subscribers can only read as far as the abstracts. If they try to go beyond this point, they are automatically asked, whether they would like to order the pdf, and are given instructions as to how to do so.

Please note that, if your email address is given in your paper, it will also be included in the meta data of the online version.

\section{Conclusion}

In this study, half of the current country of close to 60 years of age or older showed that without the old year. Statistics 2013 published results of the social survey, $48.4 \%$ of 60 years old or older population has been estimated that in old age without preparation, that reason is the $58.1 \%$ answered that there is no capacity to prepare for retirement. In addition, $38.6 \%$ of seniors aged 60 and over is cited as the economic problems that are currently facing the biggest challenges.

In particular, the welfare of the elderly, the welfare budget and the 2014 budget was 2.0507 trillion won increased compared to 6 billion won in 2013, 34444 trillion 2937 billion. However, most seem to be impressed ( 97,100 $\rightarrow 20$ million) with the basic old-age pension Maximum salary. In other words, based on the old-age pension it is increased by 5 trillion 2002 budget billion won in 2014, 2,099 billion won in Article 3 trillion in 2013 increased by 9,990 billion won. This commitment was recognized as being the mark of a true general election, rather than the introduction of the Elderly will increase the budget.

In fact, only a general and universal welfare of older than the well-being of lowincome elderly is recognized as being automatically given. So the welfare budget of lowincome elderly and the welfare of the underprivileged in our society despite being operated is increased as it is being left in the blind spot. Housing problems of the elderly among the various problems that arise, such as costs for managing the cost of living and housing, regardless of the presence or absence of homeownership. In other words, the economic crisis because of the low-income elderly can be a situation that can be driven in a jjokbang or distance cannot afford the housing costs.

Therefore, the present study is to present a plan to identify possible solutions, such as problems caused by living in low-income elderly in the future.

First, even if a gradual change in the budget is somewhat inevitable that it must ever acknowledge the fundamental transition to a true welfare oriented rather than recognizing the financial management of the electoral keynote table.

Second, the unconditional elderly individual salaries in the transition to ensure that the principles of the existing minimum living guarantee thorough measures should not undermine the livelihood as well as government budget cuts in salaries and rehabilitation benefits, you must carefully weigh the evidence of the emergency welfare budget and rebalance.

Third, we need to approach it carefully and thoroughly review whether it is really silik in the current social security system and adjusts the circumstances set out by the Ministry of the Basic Law, which transferred to other ministries for housing benefit in critical situations removal of the partition phenomena between departments .

Fourth, the elder welfare budget in more detail which seemingly have increased the salary hikes in accordance with the basic pension introduced as you see reflected in the view because it is actually an increase in the welfare budget of low-income elderly people should be the welfare organization.

Fifth, the choice for health insurance protection-type government, except medical expenses, higher byeongsilryo, if necessary, to include any such ganbyeongbi step should organize a subscriber budget support for the elderly. 
Sixth, the grant rate adjustments to ease the financial burden on local governments often have to try to finance expansion and ever adjusted in accordance with the amendment that the roles of central and local governments in addition to the current Social Security Basic Law on financial circumstances rather than financial circumstances welfare, etc. should meet the needs and be adjusted according to the different roles the first reference.

Finally, for the elderly welfare, social service delivery system with regards to social insurance, such as the National Pension Service in charge rather than the current vague one-stop service system, built by the government in charge of promoting long-term care insurance for the elderly and disabled Health Insurance Activity Support Authority in charge of the local social welfare facilities and operations support and public assistance services, government, and indeed ever urgent need to discuss ways to build a comprehensive social service delivery system reform Considering the private sector such as private welfare in charge of supply there is.

\section{References}

[1] C. Bergstrő, "Securum and way out of the Swedish Banking Crisis", SNS-Center for Business and Policy Studies, (2003).

[2] T. Curry and L. Shibut, "The Cost of the Savings and Loan Crisis: Truth Truth and Consequences", FDIC Banking Review, FDIC, vol. 13, no. 2, (2000).

[3] L. Jonung, "The Swedish model for resolving the banking crisis of 1991-93. Seven reasons why it was successful", Economic papers, European Commission, vol. 360, (2009).

[4] L. Davison, "Politics and Policy: The Creation of the Resolution Trust Corporation", FDIC Banking Review, FDIC, vol. 17, no. 2, (2005).

[5] S. Ingves, "Lessons Learned from Previous Banking Crises: Sweden, Japan, Spain and Mexico", Occasional Paper, the Group of Thirty, vol. 79, (2009).

[6] T. Hoshi and A. K. Kashyap, "Solutions to Japan's Banking Problems: What might work and what definitely will fail", US-Janpan Conference on the Solutions for the Japanese Economy, (2004). 
International Journal of $u-$ and $e-$ Service, Science and Technology Vol.8, No. 7 (2015) 